\title{
O sujeito autista na Rede SUS: (im)possibilidade de cuidado ${ }^{\star}$
}

\author{
Lucas Silveira da Silva, (iD I, ${ }^{I \star}$ Luis Achilles Rodrigues Furtado (iD II \\ ${ }^{I}$ Centro Universitário Barriga Verde, Orleans, SC, Brasil \\ ${ }^{\text {II } U n i v e r s i d a d e ~ F e d e r a l ~ d o ~ C e a r a ́, ~ F o r t a l e z a, ~ C E, ~ B r a s i l ~}$
}

\begin{abstract}
Resumo
O presente artigo visa apresentar um estudo teórico sobre os documentos oficiais e normativos do Ministério da Saúde em relação aos Transtornos do Espectro do Autismo (TEA). Partimos do objetivo de conhecer o discurso presente nesses documentos e, nesse contexto, quais relações podemos tecer entre eles e o conceito de integralidade. Utilizamos como fonte a Biblioteca Virtual em Saúde (BVS) do Ministério da Saúde, bem como alguns autores da Psicanálise que traçam uma leitura sobre o autismo no panorama científico atual. Concluímos que os documentos lançados pelo Ministério da Saúde são dissonantes, pois a Linha de Cuidado para a Atenção às Pessoas com Transtornos do Espectro do Autismo aponta filiações teóricas e uma lógica de rede distintas do apresentado nas Diretrizes de Atenção à Reabilitação da Pessoa com Transtornos do Espectro do Autismo. Além disso, erguem problemáticas que colocam em questão a possibilidade do cuidado integral na Rede do Sistema Único de Saúde (SUS).
\end{abstract}

Palavras-chave: integralidade; deficiência; foraclusão.

\section{The autistic subject in the Health Unic System: (im)possiblity of care}

\begin{abstract}
This paper aims to present a theoretical study on the official and normative documents of the Ministry of Health in relation to Autism Spectrum Disorders (ASD). We start from the objective of knowing the discourse present in these documents and, in this context, what relations we can weave between them and the concept of integrality. We used as a source the Virtual Health Library (VHL) of the Ministry of Health, as well as some authors of Psychoanalysis who draw a reading about autism in the current scientific panorama. We conclude that the documents released by the Ministry of Health are dissonant, since the Care Line for the Care of People with Autism Spectrum Disorders points out theoretical affiliations and a network logic different from the one presented in the Directives of Attention to the Rehabilitation of the Person with Disorders of the Spectrum of Autism. In addition, they raise issues that call into question the possibility of integral care in the Network of the Unified Health System (SUS).
\end{abstract}

Keywords: integrality; deficiency; forclusion.

\section{Introdução}

Atualmente denominado Transtorno do Espectro Autista (TEA) pelo Manual Diagnóstico e Estatístico de Transtornos Mentais (APA, 2013), o autismo acompanha os primórdios da Psiquiatria desde a virada do século XVIII para o XIX, inicialmente atrelado à noção de idiotia. ${ }^{1}$ No contexto de então, o tratamento moral de Pinel passou a ser questionado quanto a sua efetividade com esses pacientes, apostando-se no método clínico-pedagógico, desenvolvido pelo célebre médico francês Jean Itard (BRASIL, 2013).

Muitos fatos e uma série de acontecimentos em torno da figura do idiota/autista sucederam-se, fatos que ainda hoje permanecem, e podem-se evidenciar resquícios dessa "confusão" e ou dúvida se o quadro diagnóstico é uma psicopatologia ou deficiência. Embora o debate seja secular, os campos das neurociências e teorias comportamentais, nos dias atuais, sustentam uma visão do sujeito autista ainda atrelada à deficiência (BATISTA, 2012).

No âmago da questão encontrava-se a necessidade de distinção entre os quadros de deficiência intelectual e retardo mental e psicoses, pois até então eles eram enquadrados na mesma categoria. Entretanto, em 1818, Es-

\footnotetext{
^ Trabalho realizado com o incentivo da Fundação Cearense de Apoio ao Desenvolvimento Científico e Tecnológico (FUNCAP)

$\star \star$ Endereço de correspondência: Centro Universitário Barriga Verde. Rua Pe. João Leonir Dall'Alba, 601, Murialdo, Orleans, SC - Brasil. CEP: 88870-000. E-mails: psiclucas@gmail.com, luis_achilles@yahoo.com.br

Os dados completos dos autores encontram-se ao final do artigo.

Nos primórdios da Psiquiatria, a idiotia é considerada precursora da noção de retardo mental, psicoses infantis e o próprio autismo (BATISTA, 2012).
}

quirol propôs uma diferenciação entre loucura e idiotia, pois para a primeira haveria uma suposta cura, enquanto o idiota era mantido numa posição de incurabilidade e estigmatizado como o "degrau zero da humanidade" (ZAFIROPOULOS, 1981 apud BATISTA, 2012, p. 42).

Em 1943, Leo Kanner, médico austríaco, radicado nos Estados Unidos, publicou o artigo "Os distúrbios autísticos de contato afetivo", utilizando o termo "autismo" que Eugen Bleuler havia usado para descrever um dos sintomas da esquizofrenia, caracterizado pelo isolamento e desinteresse do indivíduo pelas pessoas e objetos externos (BRASIL, 2013). Desde então, percebemos uma história atrelada a avanços e retrocessos no âmbito científico em torno do autismo.

Relacionada à questão dos avanços e retrocessos, destaca-se, no Brasil, a criação e aprovação da Lei 12.764 (Lei Berenice Piana), de 27 de dezembro de 2012, que institui a Política Nacional de Proteção da Pessoa com Transtorno do Espectro Autista. A referida legislação passou a tomar o autista, para fins de lei, como pessoa com deficiência (BRASIL, 2012a). Este fato nos traz inúmeras repercussões, tanto no âmbito científico quanto social, visto que pais de autistas tiveram grande participação para a elaboração e aprovação da referida lei.

A partir dessa vinculação da figura do autista à deficiência temos uma série de reflexos na política pública de saúde, e nos surpreende tal vinculação atualmente por parte do governo e dos familiares, ainda que historicamente o deficiente tenha sido mais estigmatizado que o 
louco (BATISTA, 2012). Essa realidade dá margem a várias discussões. A que nos interessa é a configuração/ organização da Rede SUS no tangente à atenção/cuidado integral aos usuários autistas e os desdobramentos que a vinculação do autismo com a deficiência intelectual/ cognitiva traz no contexto em questão, a saúde pública.

\section{Documentos oficiais e normativos do Ministério da Saúde} referentes aos Transtornos do Espectro do Autismo

Para alcance do objetivo traçado no presente estudo, lançamos mão da leitura e análise dos documentos publicados pelo Ministério da Saúde nos anos de 2013 e 2014 em torno dos TEA e dos respectivos papéis dos diversos dispositivos da Rede diante do cuidado e acompanhamento dos sujeitos em questão. Dessa forma, procuramos apresentar os documentos e traçar uma reflexão teórica a partir de autores psicanalíticos que abordam o autismo e sua interface com a Saúde Pública.

O documento "Linha de Cuidado para a Atenção às Pessoas com Transtornos do Espectro do Autismo e suas Famílias na Rede de Atenção Psicossocial do Sistema Único de Saúde" foi lançado em 2013. Destinado a gestores e profissionais da Rede de Atenção Psicossocial (RAPS), ele “[...] objetiva contribuir para a ampliação do acesso e a qualificação da atenção às pessoas com Transtornos do Espectro do Autismo (TEA) e suas famílias" (BRASIL, 2013, p. 9).

O segundo material analisado foi lançado preliminarmente em 2013, sendo sua versão definitiva apresentada em 2014. Denomina-se "Diretrizes de Atenção à Reabilitação da Pessoa com Transtornos do Espectro do Autismo (TEA)" e consiste na apresentação de orientações às equipes multiprofissionais “[...] dos pontos de atenção da Rede SUS para o cuidado à saúde da pessoa com transtornos do espectro do autismo (TEA) e de sua família nos diferentes pontos de atenção da Rede de Cuidados à Pessoa com Deficiência" (BRASIL, 2014, p. 7).

Em consonância com o princípio da integralidade ${ }^{2}$ do Sistema Único de Saúde (SUS), a Linha de Cuidado objetiva uma série de medidas e recomendações para os profissionais da Rede de Atenção à Saúde (RAS), bem como apresenta uma ampla discussão em torno dos TEA, sua inserção e acolhimento na Rede SUS. Além disso, apresenta aspectos teóricos e nosológicos levantados por estudos atuais, destacando-se os das áreas genética, ciência cognitivo-comportamental e Psicanálise, dentre outras.

$\mathrm{O}$ referido documento evidencia uma ampla gama de abordagens, teorias e evidências científicas em torno do tema, salientando a pluralidade de visões acerca dos TEA, além de uma breve contextualização do autismo (BRASIL, 2013). Essa amplitude talvez se justifique pelo fato de o documento ter sido disponibilizado para Consulta Pública,

O SUS é uma política pública que possui três princípios norteadores, quais sejam: universalidade, integralidade e equidade. A universalidade parte da garantia de acesso de todo e qualquer cidadão aos serviços públicos de saúde. A integralidade, por sua vez, deve ser pensada a partir de duas dimensões, a primeira voltada ao reconhecimento de um sujeito integral, e a segunda, a uma rede de cuidados que tenha a capacidade resolutiva dessa demanda diversificada. Já o princípio da equidade intenta evitar iniquidades e/ou desigualdades na assistência e acesso aos serviços de saúde (BRASIL, 1990). No presente estudo, privilegiamos o conceito integralidade devido aos objetivos propostos, que circulam em torno do sujeito e de uma rede de serviços com capacidade de oferta do cuidado integral. sendo possível a elaboração e acompanhamento democrático por parte de cidadãos, profissionais da saúde e pesquisadores interessados, para posterior publicação oficial.

Salientamos que o documento Linha de Cuidado, em relação à sua elaboração, contou com a participação de profissionais da Rede de Atenção Psicossocial (RAPS) e Coordenação Geral de Saúde Mental Álcool e outras Drogas, instituições estruturadas a partir dos ideais levantados pelo processo de Reforma Psiquiátrica, além de profissionais da Psiquiatria e Psicologia. Ressaltamos, igualmente, a participação de representantes de outras áreas técnicas do Ministério da Saúde no processo de elaboração da Linha de Cuidado, tais como: Área Técnica da Pessoa com Deficiência, Aleitamento Materno, Rede de Urgência e Emergência, assim como representantes intersetoriais, dentre eles o Ministério da Educação e o Ministério do Desenvolvimento Social e Combate à Fome.

Portanto, podemos afirmar que o lugar de referente e/ ou agente discursivo da Linha de Cuidado posiciona-se em consonância com os conceitos e égides erguidos pelo processo de reforma psiquiátrica, bem como com o conceito de intersetorialidade. Nessa dinâmica, percebemos vários posicionamentos e lugares, o que enriquece o diálogo em torno da temática.

A Linha de Cuidado possui 160 páginas e está dividida em um capítulo introdutório, seguido de cinco capítulos. Sua introdução versa sobre os objetivos da Linha de Cuidado, reafirmando os princípios ético-técnico-políticos para a organização dos pontos de atenção na Rede de Atenção Psicossocial (RAPS). Além disso, situa a Saúde Pública como direito previsto na Constituição Federal (BRASIL, 1988), bem como na Lei n 8.080 de 19 de setembro de 1990 (Lei Orgânica da Saúde [BRASIL, 1990]). Dessa forma, direciona o leitor acerca da organização e características da RAPS, salientando sua estruturação e influências em relação aos ideais levantados pela Reforma Psiquiátrica e o conceito de território.

O capítulo um da Linha de Cuidado, "Transtornos do Espectro do Autismo: construção histórica do conceito, da definição e da nomenclatura", apresenta os precursores do autismo, bem como sua relação e afiliação aos transtornos mentais e transtornos do desenvolvimento. No capítulo seguinte, "Avaliação e diagnóstico dos transtornos do espectro do autismo", são delineados o processo diagnóstico do transtorno, sua detecção precoce e respectiva classificação diagnóstica.

No capítulo três da Linha de Cuidado, denominado "Diretrizes para o cuidado", são apresentados os conceitos de integralidade, garantia de direitos, além disso, são discutidos os arranjos organizacionais da Rede de Atenção à Saúde (RAS), bem como o Projeto Terapêutico Singular (PTS) e algumas tecnologias de cuidado que devem ser disponibilizadas na rede. O capítulo quatro, por sua vez, versa sobre a organização da Rede de Atenção Psicossocial e a respectiva articulação entre seus pontos, sejam eles da Atenção Primária à Saúde, Estratégia Saúde da Família (ESF), Núcleo de Apoio à Saúde da Família (NASF), e demais níveis de atenção. 
O último capítulo, denominado "Redes e articulações intersetoriais", traz a necessidade das parcerias que devem ser estabelecidas entre Saúde, Assistência Social e Educação para a garantia de direitos das pessoas com Transtornos do Espectro do Autismo. Nesse sentido, apresenta a Política Nacional de Educação Inclusiva, em parceria com a Assistência Social, e a perspectiva da Convenção dos Direitos das Pessoas com Deficiência em relação aos TEA.

\section{Psicanálise, autismo e Saúde Pública: panorama atual}

O Autismo vem sendo tratado pela mídia, ciência e diversos movimentos com certa ênfase nos últimos anos. Cercado de mistérios e jogos políticos, o autismo tem se tornado objeto de pesquisas e debates incessantes, sendo a figura do autista entronizada, pairando sobre si um certo fascínio (FURTADO, 2013). No entanto, apesar das inúmeras contribuições para a compreensão não só do autismo, mas de outras psicopatologias, a Psicanálise, em determinadas situações, é afastada por um discurso pseudocientífico, no qual a psiquiatria nosológica e as neurociências imperam com certo absolutismo. Essa realidade aponta para uma tendência à "biologização" dos transtornos mentais (PARDO; ALVAREZ, 2007).

Em consonância com essa questão, Elia (2014, p. 19) nos fala da obscuridade do cenário científico atual, que reduz a ciência a "repetição de chavões, protocolos, esquemas estéreis de pensamento". Nesse sentido, assistimos a certo repúdio a toda e qualquer forma de compreensão da subjetividade de sujeitos em sofrimento psíquico. Destacamos aqui uma certa aversão à teoria psicanalítica. Como aponta Elia (2014), essa aversão à Psicanálise é uma estratégia política perversa para controle dos sujeitos e medicalização de seus sintomas, cuja remissão imediata é necessária!

Essa é a receita na qual os interesses dominantes se sustentam, tornando o sujeito extremamente subordinado a uma lógica que o excluiu do processo, uma espécie de foraclusão ${ }^{3}$ da dimensão subjetiva no mundo contemporâneo, e, concomitantemente, do autismo, como aponta Furtado (2013). Desse modo, assistimos a uma certa aversão a toda e qualquer tentativa de ampliação e compreensão crítica do autismo, pois há uma supervalorização de estudos genéticos e abordagens comportamentais em detrimento de outras maneiras de se pensar/refletir sobre o objeto em que nos debruçamos.

Partindo da crítica a essa "tendência atual" da busca do substrato biológico para todo e qualquer transtorno mental, cujo modelo de ciência é pautado pelo objetivismo exacerbado, vemos uma tentativa de transposição deste modelo teórico-conceitual para o campo da Psicanálise, acusada de utilizar métodos tendenciosos e demasiadamente subjetivos. Definitivamente, tal acusação é totalmente infundada, porque a tecnociência e a teoria psicanalítica não tratam da mesma questão. Esta convoca o sujeito a produzir o saber e não o trata como objeto passível de aplicação de determinado conhecimento como aquela (ELIA, 2014).

\footnotetext{
Repúdio e/ou rejeição ao significante "Nome-do-Pai", mecanismo implicado na estrutura psicótica (ROUDINESCO; PLON, 1998).
}

Entendemos que o diálogo se faz imprescindível em torno do autismo; partilhamos da ideia de que não existe uma abordagem messiânica que consiga elucidar todas as características da questão. Entretanto, a Psicanálise precisa de um espaço nesse cenário, para convocar o sujeito e evidenciar os desafios que se apresentam no campo da Saúde Pública. Referindo-se ao alcance ínfimo da Psicanálise no contexto social e histórico em que ela se esboçara, Freud, em 1919, supôs que no futuro a Psicanálise adentraria instituições ou clínicas em que os atendimentos seriam gratuitos e ofertados aos vários segmentos populacionais menos favorecidos economicamente. No entanto, neste contexto futuro, teríamos a tarefa de "[...] adaptar a nossa técnica às novas condições" (FREUD, $1919[1918] / 2006$, p. 105).

Nesse sentido, é mister a inserção da Psicanálise no campo do autismo e Saúde Pública para uma abordagem do sujeito integral, bem como na busca de um diálogo possível com as demais concepções/abordagens. Não desejamos pairar num ostracismo teórico-prático, pois se assim procedêssemos ocultaríamos o sujeito, que, pelo contrário, procuramos evidenciar. E, como Freud descrevera, não podemos evitar, tratando-se da abordagem de alguns pacientes "incapazes da vida comum", uma combinação da "influência analítica com a educativa" (FREUD, 1919[1918], p. 103).

Dessa maneira, ressaltamos que o conceito de sujeito aqui tomado pelo estudo está em consonância com a Psicanálise, ou seja, regido por um desejo que não possui "inscrição biológica ou código da natureza" (BEZERRA, 2013, p. 65), sujeito este constituído a partir da alienação ao Outro, seguindo uma ótica lacaniana. Nessa problemática, Ribeiro (2012) ressalta que a questão central no autismo é que no processo de constituição psíquica não houve a operação de alienação e separação, o que explica a dificuldade do autista em lidar com a linguagem e o processo de comunicação com o outro.

Nesse contexto, torna-se imprescindível introduzirmos a temática da integralidade, um princípio do SUS que consiste na oferta de um "conjunto contínuo e articulado de ações e serviços preventivos e curativos, individuais e coletivos, em todos os níveis de complexidade do sistema" (BRASIL, 1990, p. 4). Somada a essa definição constante na Lei 8.080 (BRASIL, 1990), também chamada Lei Orgânica da Saúde, há a necessidade de incluir os aspectos processuais, individuais, coletivos e singulares de cada sujeito (ANDRADE; COSTA, 2010).

A letra da referida legislação traz consigo uma série de prerrogativas ao usuário do SUS, tomando-o em sua integralidade, ofertando serviços que abarquem suas esferas "biopsicossociais", de modo a não compartimentá-lo - uma das problemáticas sobre a qual nos debruçamos.

Ao trazer o conceito de integralidade como a principal diretriz de cuidado às pessoas com TEA, conforme apontado na Linha de Cuidado, tomamos a discussão na sua dimensão complexa. Penetramos, assim, nos campos da assistência propriamente dita, na dimensão político- 
-científica que circunda a realidade não só da Rede de Atenção Psicossocial (RAPS), como também de outros pontos que fazem a conexão intersetorial com esta.

A respeito da integralidade, a Linha de Cuidado aponta que "Esta concepção de sujeito e cuidados se coloca em oposição à ineficiência produzida pela visão fragmentada dos sujeitos e segmentação de ações e serviços, que tem como consequência a segregação e exclusão da população em questão" (BRASIL, 2013, p. 64). Este debate se torna uma necessidade no seio da Saúde Pública e ao mesmo tempo uma problemática para nosso estudo. Vejamos!

Historicamente, temos uma lógica de rede que se mostra fragilizada. Um dos vários fatores dessa fragilização circula em torno de uma visão fragmentada e segmentada das ações e serviços, cujo resultado é uma segregação e alguma exclusão da dimensão subjetiva não só da população com TEA, mas dos demais sujeitos em sofrimento psíquico.

É consensual, entre muitos autores, a contradição entre o conceito de integralidade e a hegemonia do modelo biomédico, que centra a compreensão da doença nos aspectos e alterações fisiológicas. Há uma desvalorização dos determinantes sociais e subjetivos em saúde; dessa forma, reduz-se e/ou minimiza-se tanto a compreensão acerca da experiência de adoecimento como a assistência a uma série de procedimentos e protocolos baseados em evidências (ANDRADE; COSTA, 2010; ROSSONI; LAMPERT, 2004; HORA et al. 2013; GAZZINELLI et al. 2005; OLIVEIRA, 2002).

Essa leitura nos direciona ao conteúdo da Linha de Cuidado citada acima, pois, ao tratar das diversas teorias e técnicas contidas no documento, para lançar uma reflexão sobre os TEA e as perspectivas a serem seguidas na Rede SUS para a atenção a essas pessoas, vemos um discurso que aponta primordialmente para a necessidade da integralidade do cuidado. Nesse sentido, o documento indica a necessidade de assegurar um processo diagnóstico que leve em consideração o caráter singular da pessoa, sua história e características únicas, "fornecendo o contexto indispensável à compreensão do sofrimento ou transtorno mental de cada sujeito" (BRASIL, 2013, p. 45b).

Destacamos, no trecho citado acima, a (im)possibilidade da Linha de Cuidado no tangente à oferta da integralidade, com o intuito de problematizar e evidenciar que tratamos de posicionamentos que, ao longo do texto, mostram-se antagônicos. Justificamos tal posicionamento, pois as tendências científicas atuais adotadas no documento apresentam uma concepção de sujeito em contínua alternância, ou seja, entre a deficiência e transtorno mental, a primeira como mental disability, enquanto a segunda como categoria nosológica psiquiátrica. Quais saídas podemos visualizar diante de tais constatações?

Desta forma, o autista transita em alguns momentos, no discurso contido na Linha de Cuidado, entre a Rede de Atenção Psicossocial (RAPS) e a Rede de Cuidados à Pessoa com Deficiência. Afinal, qual é o lugar do sujeito autista na Rede SUS? Essa questão nos intriga, pois o próprio documento parece não definir com precisão o lugar que deve ser ocupado por esse sujeito na Rede, embora, prioritariamente, cite a RAPS. Ao trazermos essa problematização, não queremos jamais limitar o sujeito a um ponto da rede, ou da RAPS, ou da Rede de Cuidados à Pessoa com Deficiência, mas sim ampliar a discussão em torno do autismo e do conceito de integralidade e, principalmente, descortinar as contradições existentes em torno da temática.

A RAPS possui diversos dispositivos, dentre os quais podemos destacar o Centro de Atenção Psicossocial (CAPS), que é um serviço comunitário, substitutivo dos hospitais psiquiátricos, e que deve operar de "portas abertas, sem barreira de acesso ou agendamento" (BRASIL, 2013, p. 102). Pode ser considerado como um dos serviços de referência às pessoas com TEA, possuindo como estratégia a oferta de serviços como: atendimentos individuais ou em grupo, atividades comunitárias e de reabilitação psicossocial ${ }^{4}$, tratamento medicamentoso, entre outros. Nos últimos anos os CAPS têm se destacado pela oferta de Apoio Matricial às Equipes de Saúde da Família, desenvolvendo, dessa forma, a potencialização da capacidade resolutiva das equipes da ESF em assuntos/problemas voltados à saúde mental (BRASIL, 2013).

Se nos remetemos à RAPS, por que falar em deficiência intelectual e/ou cognitiva? Afinal, qual o lugar do autista na rede?

A Rede de Cuidados à Saúde da Pessoa com Deficiência constituirá uma oferta importante de atenção à saúde das pessoas com TEA, uma vez que, frequentemente, estão presentes alterações cognitivas, de linguagem e de sociabilidade, que afetam diretamente - com maior ou menor intensidade - grande parte das pessoas com TEA, limitando capacidades funcionais no cuidado de si e nas interações sociais, o que demanda cuidados específicos e singulares de habilitação e reabilitação (BRASIL, 2013, p. 115-116).

Essa questão nos faz mergulhar num paradigma histórico, conforme apontado acima, acompanhando a discussão em torno das idiotias versus loucura. Apesar de a Linha de Cuidado priorizar a discussão do acompanhamento da pessoa com TEA na RAPS, traz, mesmo assim, a articulação com a Rede de Cuidados à Saúde da Pessoa com Deficiência (BRASIL, 2013). Dessa forma, evidenciamos inúmeras problemáticas, pois, mesmo que a pessoa com TEA seja considerada deficiente para fins de lei, qual o lugar desse sujeito na rede? Qual a noção de deficiência adotada por esses documentos?

No momento em que há uma associação do sujeito autista a uma deficiência intelectual, mesmo que para fins de lei, temos uma paráfrase, ou retorno aos primórdios da discussão em torno da idiotia versus loucura. As abordagens utilizadas na Rede de Atenção à Saúde (RAS), mais especificamente na RAPS, devem apontar para uma "narrativa aberta" no processo de diagnóstico e cuidado (BRASIL, 2013, p. 37).

${ }^{4}$ A reabilitação Psicossocial consiste na inserção do usuário em atividades econômicas e comunitárias, fortalecendo o vínculo e sentimento de pertença a determinada comunidade, visando a ampliação de laços sociais (BEZERRA, 2013). 
Desta forma, eis uma questão central nesta discussão: podemos falar em singularidade e narrativa aberta para pessoas com TEA, mesmo limitando-as ora a uma nomenclatura diagnóstica que dita o prognóstico para esses sujeitos, ora à categoria deficiência, incapacitando-as sob as regras desenvolvimentistas construídas por um discurso voltado à reabilitação? Esse questionamento se encaixa no estudo, pois nos propomos a analisar o discurso dos documentos lançados pelo Ministério da Saúde, e a Linha de Cuidado aborda essa questão.

Embora a Linha de Cuidado faça referência especialmente à RAPS, Bezerra (2013) revela em seu estudo que a singularidade nem sempre é levada em consideração na rede de saúde mental. A autora afirma que sujeito do inconsciente é foracluído nos diversos dispositivos dessa rede. Assim, seguimos e/ou nos moldamos por uma lógica política e científica da contemporaneidade, na qual a "ciência moderna" torna-se um poderoso modo de controle social dessas instituições que deveriam estar a serviço da escuta e não somente do olhar (BEZERRA, 2013). A autora utiliza a dimensão da escuta atrelada à clínica psicanalítica e a clínica do olhar ao saber psiquiátrico, que, em consonância com a leitura de Foucault, remete a busca do "verdadeiro essencial sob a individualidade", lançando um olhar diferenciado sobre a história de constituição da clínica (FOUCAULT, 2004, p. 106 apud BEZERRA, 2013, p. 32).

Mesmo constatada a dificuldade de se chegar ao cuidado integral devido à ambiguidade presente na narrativa da Linha de Cuidado, o documento aponta uma alternativa para assegurar tal princípio do SUS. Desta forma, por meio do Projeto Terapêutico Singular (PTS), supostamente podemos consolidar a integralidade. O PTS, nesse sentido, consiste no "direcionamento das ofertas de cuidado construído a partir da identificação das necessidades dos sujeitos e suas famílias nos contextos reais de vida, englobando diferentes dimensões" (BRASIL, 2008 apud BRASIL, 2013, p. 77). O PTS deve ser conduzido e acompanhado pelos profissionais da equipe de referência e demais atores sociais envolvidos no continuum do cuidado, destacando-se que não deve restringir-se às ações e tecnologias intrassetoriais, necessitando englobar neste processo as ações intersetoriais.

Entretanto, podemos perceber, num documento apenas, uma confusão oriunda da dissonância de opiniões e posicionamentos. Neste sentido, acreditamos que há necessidade real da revisão do conteúdo da Linha de Cuidado, pois o diálogo entre as partes ressoa no todo. Essa questão nos aponta quão complexo é o autismo e o quanto sabemos pouco sobre ele.

Ratificamos, desta forma, como levantado anteriormente, que nenhuma abordagem e/ou tecnologia elucidará em sua totalidade a complexidade do autismo. No campo da Saúde Pública, na conjuntura da Rede SUS, não devemos cristalizar o processo de cuidado, pois este deve ser plural e singular ao mesmo tempo. Plural, pois necessita de uma rede integral que disponha de diversas tecnologias de cuidado para sanar demandas; e singular, pois é construído a partir das premissas e desejos do sujeito.
As tecnologias de cuidado trazem essa dimensão complexa em torno do autismo, sinalizando que não deve haver privilégio entre uma abordagem e outra (BRASIL, 2013). Entretanto, há claras evidências da priorização pelas abordagens "objetivas", visto que estas possuem evidências científicas. Dentre as abordagens citadas no documento destacamos: tratamento clínico de base psicanalítica, Análise do Comportamento Aplicada (Applied Behavioral Analysis), Comunicação Suplementar e Alternativa (CSA), Integração Sensorial, Tratamento e Educação para crianças com Transtornos do Espectro do Autismo (TEACCH), dentre outros.

\section{Autismo, transições conceituais e implicações nos arranjos organizativos da Rede SUS}

A leitura dos documentos ministeriais remete-nos à discussão acerca da historicidade da saúde mental no Brasil, bem como ao processo de Reforma Psiquiátrica. Apesar dos avanços da letra no tangente aos direitos dos usuários dos serviços ligados à RAPS, podemos localizar pontos de divergências, convergências de saberes e técnicas priorizadas em cada ponto dessa rede. Para isso, vamos nos situar na primeira contradição constatada no referente ao autismo, as transições entre transtorno do desenvolvimento, transtorno mental/espectral e deficiência.

Essas transições de perspectivas e posicionamentos são evidentes entre os documentos Linha de Cuidado e Diretrizes de Atenção, pois o primeiro traz uma discussão ao mesmo tempo ampla e problemática sobre os TEA, enquanto o segundo reduz o quadro a uma deficiência intelectual, passível de tratamento e reabilitação na Rede de Cuidados à Pessoa com Deficiência.

$\mathrm{O}$ documento "Diretrizes de Atenção à Reabilitação da Pessoa com Transtornos do Espectro do Autismo (TEA)" possui 85 páginas, está dividido em doze capítulos e resulta de uma pesquisa bibliográfica que utilizou material nacional e internacional dos últimos 70 anos a respeito da problemática. Desta forma, contou com a colaboração de "[...] profissionais, pesquisadores e especialistas com experiências reconhecidas em diversas profissões da área da Saúde e pertencentes a sociedades científicas e profissionais" (BRASIL, 2014).

$\mathrm{O}$ objetivo desta diretriz é oferecer orientações às equipes multiprofissionais dos pontos de atenção da Rede SUS para o cuidado à saúde da pessoa com transtornos do espectro do autismo (TEA) e de sua família nos diferentes pontos de atenção da Rede de Cuidados à Pessoa com Deficiência (BRASIL, 2014, p. 7).

As diretrizes foram elaboradas, especialmente, pelos profissionais das áreas de Fonoaudiologia ${ }^{5}$ e Neurologia e pelos representantes da Coordenação Geral de Saúde da Pessoa com Deficiência. Assim, podemos perceber uma filiação direta do documento ao campo da deficiência e numa perspectiva voltada à reabilitação. Nesse sentido, destacamos o lugar do qual o documento que ora analisamos nos fala, salientando sua filiação teórica e seu

${ }^{5}$ A diretriz contou com a participação majoritária de profissionais da Fonoaudiologia, cinco, especificamente. Ressaltamos que as funções de coordenação e organização desse documento foram exercidas por esses profissionais. 
posicionamento diante da problemática do autismo, pois essas são questões imprescindíveis na Análise de Discurso francesa (ORLANDI, 2001).

Além das características citadas acima, as diretrizes possuem os seguintes eixos norteadores: Convenção sobre os Direitos da Pessoa com Deficiência de 2007, Decreto $n^{\circ} 6.949$ (BRASIL, 2009), Rede de Cuidados à Pessoa com Deficiência e Lei n ${ }^{\circ} 12.764$ (BRASIL, 2012a), instâncias essas totalmente direcionadas ao campo das deficiências (BRASIL, 2014).

Iniciamos com a descrição do capítulo dois, ${ }^{6}$ que apresenta a metodologia utilizada para a elaboração do relatório, seguido do capítulo introdutório, que apresenta o histórico em torno do autismo desde a concepção inicial de Leo Kanner até a atual classificação denominada "TEA". Dessa forma, podemos perceber que as diretrizes utilizam como marco referencial a suposta "descoberta" de Kanner dos "distúrbios autísticos de contato afetivo", em 1943. Nessa discussão, é interessante sublinhar que na versão preliminar das diretrizes constava que o autismo era considerado uma "síndrome neuropsiquiátrica" (BRASIL, 2014, p. 14); na versão definitiva, ao contrário, temos uma "amenização" desse discurso determinista.

Embora uma etiologia específica não tenha sido identificada, estudos sugerem a presença de alguns fatores genéticos e neurobiológicos que podem estar associados ao autismo, tais como anomalia anatômica ou fisiológica do sistema nervoso central (SNC) e problemas constitucionais inatos predeterminados biologicamente (AKSHOMOFF, 2006 apud BRASIL, 2014, p. 13).

Ainda que tenha descartado o termo "síndrome neuropsiquiátrica", o documento apresenta predominantemente um discurso voltado à síndrome. Justificamos, assim, a ênfase dada ao trabalho de Sir Michael Rutter em 1978 e sua "[...] fundamental importância para o desenvolvimento do conhecimento na área". Rutter foi o responsável pela caracterização da "síndrome" em relação ao nível de desenvolvimento "neuropsicomotor e cronológico" (BRASIL, 2014, p. 13). Nesse sentido, podemos evidenciar e constatar quais as filiações teóricas e posicionamento das Diretrizes de Atenção em relação ao autismo, que em seu conteúdo e textualidade é uma síndrome.

Em "Importância da detecção de sinais iniciais de problemas de desenvolvimento", capítulo seguinte das Diretrizes de Atenção, o documento traz a importância da detecção precoce de problemas no desenvolvimento, justificando o fato de que "a maior plasticidade das estruturas anátomo-fisiológicas do cérebro nos primeiros anos de vida e o papel fundamental das conexões neuronais para a constituição psicossocial tornam este período um momento sensível e privilegiado para intervenções" (BRASIL, 2014, p. 16).

Para ilustrar, o documento traz os indicadores de desenvolvimento e sinais de alerta para TEA nas esferas da interação social, linguagem, brincadeiras e alimentação.

${ }^{6} \mathrm{O}$ primeiro capítulo apresenta o objetivo do documento, questão ressaltada anteriormente.
Essas esferas são apresentadas nas seguintes faixas etárias: de zero a 6 meses; de 6 a 12 meses; de 12 a 18 meses; de 18 a 24 meses; e de 24 a 36 meses (BRASIL, 2014).

No capítulo 5 das diretrizes são apresentados os "Indicadores Comportamentais de TEA", salientando os prejuízos motores, sensoriais, rotinas, fala e aspecto emocional. Entretanto, o documento aponta que tais indicadores não são um bom preditor para TEA, pois “[...] várias crianças com TEA não os apresentam e, quando os têm, costumam demonstrá-los mais tardiamente" (BRASIL, 2014, p. 33).

O capítulo 6 aponta os principais instrumentos diagnósticos para rastreamento/triagem de indicadores de desenvolvimento infantil e dos TEA. Dessa forma, salienta que os instrumentos são importantes para a identificação de problemas específicos, pois o diagnóstico de TEA ainda "[...] permanece essencialmente clínico e é feito a partir de observações [...]" (BRASIL, 2014, p. 36).

Em "Avaliação diagnóstica e classificações" o documento das diretrizes traz a importância do diagnóstico nosológico, além de ressaltar o papel da equipe interdisciplinar em face desse processo. Nesse sentido, a diretriz aponta que as equipes devem contar com os seguintes profissionais: psiquiatra e/ou neurologista e/ou pediatra, psicólogo e fonoaudiólogo (BRASIL, 2014).

A cada profissional corresponde uma série de atribuições elencadas abaixo, conforme aponta a diretriz:

A avaliação médica, independentemente da especialidade, inclui anamnese e exame físico e, se necessário, exames laboratoriais e de imagem. Quando existirem, por exemplo, alterações emocionais e comportamentais muito importantes, alterações de sono, apetite, consciência, marcha, excesso de agressividade e agitação psicomotora que necessitem de avaliação mais precisa e de intervenções medicamentosas, geralmente é recomendada a atuação dos especialistas das áreas de neurologia e/ou psiquiatra (BRASIL, 2014, p. 39-40).

Quanto aos profissionais da Fonoaudiologia e Psicologia, ao primeiro corresponde a avaliação dos aspectos linguísticos, traçando dessa forma uma distinção entre as peculiaridades dos quadros de TEA e as dos demais distúrbios de linguagem e/ou deficiências auditivas. Em relação ao profissional da Psicologia, o documento aponta a competência para avaliações cognitivas e neuropsicológicas.

No capítulo "Comorbidades e causas" são apresentadas as principais características sintomatológicas dos quadros de TEA e a associação destes a causas genéticas, indicando as estatísticas de alguns estudos na área. Dessa forma, o documento discute a possibilidade da existência de duas sintomatologias de quadros diagnósticos distintos no indivíduo com TEA, principalmente no tangente à Deficiência Intelectual e TEA (BRASIL, 2014).

As Diretrizes de Atenção seguem com os capítulos "O momento da notícia do diagnóstico de TEA", "Projeto Terapêutico Singular: habilitação e reabilitação da pessoa com TEA", "Apoio e acolhimento da família da pessoa com TEA" e, por fim, "O fluxograma de acompanhamento e atendimento da pessoa com TEA na Rede SUS". Nesse sentido, deter-nos-emos na questão da habilitação e reabilitação, visto que essa questão é proble- 
mática, pois percebemos que o documento que lança as diretrizes possui um discurso predominantemente determinista e voltado às neurociências.

A discussão em torno da (re)habilitação é problemática e passível de análise quando se toma como questão a centralidade do cuidado integral. Ao se propor uma reabilitação ao sujeito autista, denotamos um anterior estado de normalidade e percebemos o condicionamento do discurso de profissionais e familiares carregados de um aspecto desenvolvimentista atrelado à adaptação de um "indivíduo" à norma social.

Seguindo esse parâmetro, percebemos o quanto o discurso de profissionais, familiares e demais atores sociais envolvidos no processo de cuidado está impregnado pela noção biomédica de deficiência, segundo a qual um indivíduo incapaz e denominado "paciente" deve ser reabilitado seguindo as diretrizes desenvolvimentistas (BATISTA, 2012).

Ressaltamos ainda que, embora haja um amplo debate da deficiência sob a ótica do Modelo Social de Deficiência, ${ }^{7}$ o referido documento parece priorizar o campo biomédico, este calcado nos saberes médicos, psicológicos e de reabilitação (DINIZ, 2007). O Modelo Social de Deficiência, ${ }^{8}$ de acordo com Diniz (2007), é um contraponto à lógica biomédica de abordar as deficiências, ou seja, estende essa questão ao campo das ciências humanas, especialmente à sociologia. Reconhece-se, no modelo social, tanto o corpo com lesão quanto a estrutura social que impõe restrições à participação social efetiva de sujeitos. Dessa forma, deficiência não pode ser categorizada apenas como uma restrição de funcionalidade ou habilidade, como tradicionalmente o modelo biomédico de deficiência vem definindo, cuja cura circula em torno de uma reabilitação. Essa dinâmica exige mais que isso, exige acessibilidade, exige integralidade!

A avaliação sistemática do processo de habilitação/reabilitação deve ser pautada pela consideração da linguagem, dos sentimentos, dos pensamentos e das formas que o paciente tem de se relacionar com as pessoas e com o seu ambiente, bem como pela melhoria e pela ampliação das capacidades funcionais do indivíduo em vários níveis e ao longo do tempo (BRASIL, 2014, p.63-64, grifo nosso).

De acordo com Batista (2012), o conceito de reabilitação teve grande desenvolvimento no século XX, embora seja preponderante a ideia central de reparação de um déficit adquirido. Atualmente está sendo incorporada a noção de "habilitação" na tentativa de ampliar e entender o conceito de deficiência, acoplando, nesse sentido, não somente intervenções para "melhorar a função corporal" dos sujeitos, mas também medidas abrangentes de inclusão (BATISTA, 2012, p. 48).

\footnotetext{
Surgiu no Reino Unido nos anos 1960; um de seus precursores foi Paul Hunt, so-

ciólogo e deficiente físico. $\mathrm{O}$ autor procurou ampliar o conceito de deficiência utilizando o conceito de estigma social proposto por Erving Goffman (DINIZ, 2007).

${ }^{8}$ Além do Movimento Social de Deficiência, podemos citar o movimento da neurodiversidade, organizado por autistas de alto funcionamento, geralmente diagnosticados com Síndrome de Asperger, que consideram o autismo não uma doença, mas uma diferença humana (ORTEGA, 2008).
}

Fractal, Rev. Psicol., v. 31 - n. 2, p. 119-129, 2019
Por esse ângulo, o Brasil, como signatário e Estado membro da Convenção das Nações Unidas sobre os Direitos das Pessoas com Deficiência, realizada em Nova York em 2007, lança uma série de medidas e ações inclusivas. No contexto do presente estudo, destacamos: a criação da Apacs (Autorização de Procedimentos Ambulatoriais de Alta Complexidade/Custo), em 2002, dos novos procedimentos para os "Transtornos do Desenvolvimento", em 2008, e da Rede de Cuidados às Pessoas com Deficiência e os Centros Especializados de Reabilitação II, III, IV (BATISTA, 2012).

A tentativa de limitar o autismo ao campo das deficiências sob uma perspectiva biomédica, por parte do modelo de ciência que aqui criticamos, dificulta o diálogo entre o cuidado e o princípio da integralidade, visto que este princípio, além de buscar um cuidado singular através do estabelecimento de um PTS, visa, igualmente, à escuta do sujeito autista, dinâmica que tornaria possível a inserção deste no laço social, não o reduzindo a uma entidade nosológica, cujos sintomas são descritos por manuais.

De acordo com Batista (2012), para o autista o Outro é ameaçador, enquanto para o débil o Outro é absoluto. Desta forma, deixamos claro que, quando falamos no autista, remetemo-nos a uma posição subjetiva e não apenas a um quadro caracterizado por prejuízos e incapacidades da ordem das faculdades mentais e habilidades cognitivas.

O trabalho clínico psicanalítico abre possibilidades para que cada um possa construir laços sociais, sorver a celebração de viver e contribuir para uma sociedade humana. O que interessa é que a pessoa com autismo usufrua da vida com todas as suas potencialidades, com um futuro em que há caminhos a escolher e percorrer (PACHECO, 2012, p. 105).

É imprescindível acrescentar à discussão que a Linha de Cuidado foi submetida à Consulta Pública, enquanto o segundo documento é uma diretriz cujo objetivo central é "oferecer orientações às equipes multiprofissionais". Este último documento foi elaborado por pesquisadores e "especialistas" reconhecidos nas áreas da saúde e sociedades científicas, e não foi submetido à Consulta Pública (BRASIL, 2014. p. 9).

O primeiro, Linha de Cuidado, salienta a pluralidade e intersetorialidade, enquanto o segundo, Diretrizes de Atenção, especifica e direciona o autismo ao campo das deficiências e a um ponto da rede apenas. Criamos o quadro abaixo para apontarmos as principais características e dissonâncias entre os dois documentos. 
Quadro 1 - Características e dissonâncias entre a Linha de Cuidado e as diretrizes terapêuticas

\begin{tabular}{|c|c|c|}
\hline Itens & $\begin{array}{l}\text { Linha de Cuidado para a atenção às pessoas com } \\
\text { Transtornos do Espectro do Autismo e suas famílias na Rede } \\
\text { de Atenção Psicossocial do Sistema Único de Saúde }\end{array}$ & $\begin{array}{l}\text { Diretrizes de Atenção à reabilitação } \\
\text { da pessoa com Transtornos do } \\
\text { Espectro do Autismo (TEA) }\end{array}$ \\
\hline Ano & 2013 & $\begin{array}{l}\text { Versão preliminar } 2013 \\
\text { Versão definitiva } 2014\end{array}$ \\
\hline Objetivo & $\begin{array}{l}\text { Contribuir para ampliação do acesso e qualificação da atenção às } \\
\text { pessoas com TEA e suas famílias. Trabalha-se, assim, com a } \\
\text { perspectiva da Linha de Cuidado, reafirmando os princípios } \\
\text { ético-técnico-políticos para organização dos pontos de atenção } \\
\text { da RAPS, subsidiando a definição de estratégias para ação, } \\
\text { incluindo a atenção básica. }\end{array}$ & $\begin{array}{l}\text { Oferecer orientações às equipes } \\
\text { multiprofissionais dos pontos de } \\
\text { atenção da Rede SUS para o cuidado } \\
\text { à saúde da pessoa com TEA e sua } \\
\text { família nos diferentes pontos de } \\
\text { atenção da Rede de Cuidados à } \\
\text { Pessoa com Deficiência. }\end{array}$ \\
\hline Diretrizes & $\begin{array}{c}\text { Integralidade, garantia de direitos e cidadania, arranjos e } \\
\text { dispositivos para o cuidado, Projeto Terapêutico Singular (PTS), } \\
\text { tecnologias de cuidado e Tratamento medicamentoso. }\end{array}$ & Habilitação/Reabilitação \\
\hline $\begin{array}{c}\text { Eixos } \\
\text { norteadores }\end{array}$ & 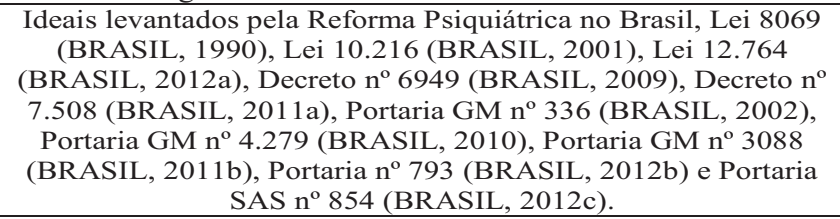 & $\begin{array}{l}\text { Convenção sobre os Direitos da } \\
\text { Pessoa com Deficiência 2007, } \\
\text { Decreto } \mathrm{n}^{\circ} 6.949 \text { (BRASIL, 2009), } \\
\text { Plano Nacional de Direitos da Pessoa } \\
\text { com Deficiência de 2011, Rede de } \\
\text { Cuidados à Pessoa com Deficiência e } \\
\text { Lei } 12.764 \text { (BRASIL, 2012a). }\end{array}$ \\
\hline $\begin{array}{l}\text { Submetido à } \\
\text { Consulta } \\
\text { Pública }\end{array}$ & Sim & Não \\
\hline Metodologia & $\begin{array}{c}\text { Não apresenta detalhamento do processo metodológico de } \\
\text { elaboração do documento. }\end{array}$ & $\begin{array}{l}\text { Pesquisa bibliográfica, resultante de } \\
\text { pesquisas científicas dos últimos } 70 \\
\text { anos/Estado da Arte. }\end{array}$ \\
\hline $\begin{array}{l}\text { Histórico do } \\
\text { Autismo }\end{array}$ & $\begin{array}{c}\text { Desde os primórdios da Psiquiatria, virada do século XVIII para } \\
\text { o XIX, debate em torno da noção de idiotia. }\end{array}$ & $\begin{array}{l}\text { Desde a caracterização do Transtorno } \\
\text { por Leo Kanner em } 1943 \text { (últimos } 70 \\
\text { anos) }\end{array}$ \\
\hline $\begin{array}{l}\text { Tecnologias de } \\
\text { Cuidado }\end{array}$ & $\begin{array}{c}\text { Tratamento clínico de base psicanalítica, Análise do } \\
\text { Comportamento Aplicada (Applied Behavioral Analysis - ABA), } \\
\text { Comunicação Suplementar e Alternativa (CSA), Integração } \\
\text { Sensorial, Tratamento e Educação para Crianças com } \\
\text { Transtornos do Espectro do Autismo (TEACCH), } \\
\text { Acompanhamento Terapêutico e Aparelhos de Alta Tecnologia. }\end{array}$ & $\begin{array}{c}\text { Não utiliza a terminologia } \\
\text { “tecnologias de cuidado", embora } \\
\text { esse seja exercido, de acordo com o } \\
\text { documento, por meio de: } \\
\text { Instrumentos de Rastreamento, } \\
\text { Avaliação Diagnóstica, entrevista } \\
\text { com pais e cuidadores, observação } \\
\text { direta do comportamento e da } \\
\text { interação, classificação diagnóstica } \\
\text { em si e, por fim, prevenção e } \\
\text { aconselhamento genético. }\end{array}$ \\
\hline $\begin{array}{l}\text { Lugar das } \\
\text { pessoas com } \\
\text { TEA na RAS } \\
\text { (Rede de } \\
\text { Atenção à } \\
\text { Saúde) }\end{array}$ & $\begin{array}{l}\text { Usuário: Rede de Atenção Psicossocial (RAPS) e seus diversos } \\
\text { pontos, sejam eles vinculados à Atenção Primária à Saúde ou } \\
\text { Serviços de Urgência e Emergência, por exemplo. }\end{array}$ & $\begin{array}{l}\text { Paciente: Rede de Cuidados à Pessoa } \\
\text { com Deficiência. }\end{array}$ \\
\hline $\begin{array}{l}\text { Ênfase nos } \\
\text { seguintes } \\
\text { aspectos }\end{array}$ & $\begin{array}{l}\text { Singularidade, narrativa aberta no processo diagnóstico, } \\
\text { integralidade do cuidado, Reforma Psiquiátrica e o conceito de } \\
\text { território, intersetorialidade e garantia de direitos. }\end{array}$ & $\begin{array}{c}\text { Detecção precoce de sinais iniciais de } \\
\text { problemas no desenvolvimento, } \\
\text { indicadores do desenvolvimento e } \\
\text { sinais de alerta, indicadores } \\
\text { comportamentais de TEA, } \\
\text { instrumentos de rastreamento e } \\
\text { avaliação diagnóstica e classificações: } \\
\text { CID } 10 \text { e CIF. }\end{array}$ \\
\hline $\begin{array}{l}\text { Processo de } \\
\text { elaboração }\end{array}$ & $\begin{array}{c}\text { Psicólogos, psiquiatras e demais profissionais vinculados à Rede } \\
\text { de Atenção Psicossocial, representantes da Coordenação Geral } \\
\text { de Saúde Mental, Álcool e Outras Drogas, além de } \\
\text { representantes do Movimento Psicanálise, Autismo e Saúde } \\
\text { Pública. }\end{array}$ & $\begin{array}{l}\text { Representantes de Sociedades } \\
\text { Científicas, Profissionais da } \\
\text { Neurologia, com participação } \\
\text { significativa nas funções de } \\
\text { coordenação e organização do } \\
\text { documento por profissionais da } \\
\text { Fonoaudiologia. }\end{array}$ \\
\hline
\end{tabular}

Fonte: Elaborado pelo autor a partir da leitura de Brasil (2013) e Brasil (2014).

Dentre as palavras presentes nas diretrizes, temos: plasticidade, quadro sintomatológico, sinais iniciais, problemas no desenvolvimento, instrumentos de rastreamento, entre outros que salientam o caráter desenvolvimentista, no qual as teorias cognitivo-comportamentais são priorizadas como produtora de verdades.

\section{Considerações finais}

Essa busca obcecada pela compreensão do suposto e referido quadro clínico leva não só a comunidade científica, mas a sociedade como um todo, a um equívoco, generalizações indevidas e necessidade de compreender um fenômeno, integralmente, a partir de uma série de ensaios clínicos e estudos genéticos. Tomam, dessa forma, o método experimental como única forma de produzir verdades em relação ao objeto que ora analisamos. 
Em face dessa leitura acerca do conceito de sujeito e autismo, vemos que há uma redução desse sujeito a uma categoria de indivíduo com uma série de sintomas, comprometimentos e incapacidades passíveis de intervenção clínico-pedagógica. De acordo com a diretriz, então, o método messiânico para intervenção no campo dos TEA é o cognitivo-comportamental, cuja finalidade é a aquisição de automatismos adaptáveis à realidade. Nessa perspectiva, aponta-nos o Grupo Gestor do Movimento Psicanálise, Autismo e Saúde Pública (MPASP), em entrevista realizada por Pacheco (2012, p. 109), "Busca-se, assim, exclusivamente a adaptação das pessoas com autismo aos padrões sociais aceitos sem considerar a singularidade de cada sujeito".

Nessa acepção, de acordo com o documento "Diretrizes de Atenção à Reabilitação da Pessoa com Transtornos do Espectro do Autismo", a rede e seus arranjos organizacionais se estruturam sob o vértice da deficiência vista na perspectiva biomédica, subjugadas a todas essas formas de saber e práticas. Então nos questionamos sobre a possibilidade ou não de termos uma "narrativa aberta" em relação aos TEA, como a Linha de Cuidado aponta ser necessário. Dois documentos, duas (im)possibilidades?

A ciência moderna e todos os seus condicionantes históricos, sociais e políticos possuem um reflexo direto na política de saúde, esse aspecto é incontestável, pois vemos avanços e outros aspectos significativos. A incorporação de tecnologias no cuidado, diagnóstico e reabilitação dos sujeitos adoecidos ou em processo de adoecimento apontam esses avanços. Esse contínuo é marcado por uma série de repercussões, sejam elas na formulação, corroboração de hipóteses, elaboração de projetos de intervenção ou no cuidado propriamente dito.

Entretanto, não podemos mascarar e encarar essa dinâmica apenas em seu aspecto "progressista", pois, assim como avançamos, retrocedemos. Ao tirarmos de cena o sujeito que está num processo contínuo de exclusão em virtude dos imperativos da evolução científica, tornando-o a variável interveniente que deve ser controlada, estamos engessando o cuidado e distanciando deste mesmo sujeito a integralidade. O discurso cientificista da prática baseada em evidências, paradigma de risco, predisposição, entre outros, deve ser transposto com o máximo de cautela para o campo da saúde mental, pois, se assim não for, correremos o "risco" de criarmos um exército de sujeitos adoecidos.

Ampliar as possibilidades de inserção do autista no laço social, produzir autonomia, levar em consideração a singularidade e garantir direitos é uma questão complexa e que se faz necessária na Rede SUS. Entretanto, restringirmo-nos às práticas e abordagens que limitam a participação do sujeito, engessam o processo de cuidado e inviabilizam a construção de uma rede viva. Para avançar é preciso discutir e convocar os diferentes saberes que abordam e lançam luz sob os fenômenos, é assim que se faz ciência. Caso contrário, estaremos reproduzindo uma lógica de imperativos supostamente científicos e legitimando o cenário obscuro atual.

\section{Informações sobre os autores:}

Lucas Silveira da Silva

(iD) https://orcid.org/0000-0002-8591-3313

(9) http://lattes.cnpq.br/4810106232967139

Possui graduação em Psicologia pela Universidade Regional Integrada do Alto Uruguai e das Missões (URI-2009), especialização em Saúde Mental e Mestrado em Saúde da Família pela Universidade Federal do Ceará.

Luis Achilles Rodrigues Furtado

(iD) https://orcid.org/0000-0003-1606-2073

(9) http://lattes.cnpq.br/7174269574652869

Professor Adjunto IV do Programa Pós- Graduação em Psicologia e Políticas Públicas da Universidade Federal do Ceará - Campus de Sobral, do Mestrado Acadêmico em Saúde da Família da Universidade Federal do Ceará - Campus de Sobral, do curso de Psicologia da Universidade Federal do Ceará - Campus de Sobral, Pós-doutor em Psicanálise na Universidade do Estado do Rio de Janeiro - UERJ, Doutor em Educação pela UFC, Mestre em Psicologia pela UFC.

\section{Contribuição dos autores:}

Lucas Silveira da Silva foi responsável pela concepção, desenho, análise, interpretação dos dados e elaboração da versão final do manuscrito. Luis Achilles Rodrigues Furtado participou do processo de análise e interpretação dos dados.

\section{Como citar este artigo:}

\section{ABNT}

SILVA, Lucas Silveira da; FURTADO, Luis Achilles Rodrigues. O sujeito autista na Rede SUS: (im)possibilidade de cuidado. Fractal: Revista de Psicologia, Niterói, v. 31, n. 2, p. 119-129, maio/ago. 2019. https://doi.org/10.22409/1984-0292/v31i2/5635

APA

Silva, L. S., \& Furtado, L. A. R. (2019). O sujeito autista na Rede SUS: (im)possibilidade de cuidado. Fractal: Revista de Psicologia, 31(2), 119-129. doi:10.22409/1984-0292/v31i2/5635

\section{Referências}

AMERICAN PSYCHIATRY ASSOCIATION. Diagnostic and Statistical Manual of Mental Disorders. 5th ed. Washington: American Psychiatric Association, 2013.

ANDRADE, João Tadeu de; COSTA, Liduina Farias Almeida da. Medicina Complementar no SUS: práticas integrativas sob a luz da Antropologia Médica. Saúde e Sociedade, São Paulo, v. 19, n. 3, p. 497-508, 2010. Disponível em: http://dx.doi. org/10.1590/S0104-12902010000300003

BATISTA, Cristina Abranches Mota. Deficiência, Autismo e Psicanálise. A peste: Revista de Psicanálise e Sociedade e Filosofia, São Paulo, v. 4, n. 2, p. 41-56, jul./dez. 2012.

BEZERRA, Daniela Santos. O lugar da clínica na reforma psiquiátrica brasileira: política e psicanálise oito anos após a Lei 10.216. Curitiba: CRV, 2013.

BRASIL. Presidência da República. Casa Civil. Subchefia para Assuntos Jurídicos. Constituição da República Federativa do Brasil de 1988. 1988. Disponível em: http://www.planalto. gov.br/ccivil_03/constituicao/constituicao.htm. Acesso em: 12 maio 2016. 
BRASIL. Presidência da República. Casa Civil. Subchefia para Assuntos Jurídicos. Lei $n^{\circ}$ 8.080, de 19 de setembro de 1990. Dispõe sobre as condições para a promoção, proteção e recuperação da saúde, a organização e o funcionamento dos serviços correspondentes e dá outras providências. 1990. Disponível em: http://www.planalto.gov.br/ccivil_03/leis/ 18080.htm. Acesso em: 12 out. 2016.

BRASIL. Presidência da República. Casa Civil. Subchefia para Assuntos Jurídicos. Lei $n^{\circ} 10.216$, de 6 de abril de 2001. Dispõe sobre a proteção e os direitos das pessoas portadoras de transtornos mentais e redireciona o modelo assistencial em saúde mental. 2001. Disponível em: http://www.planalto.gov. br/ccivil_03/leis/leis_2001/110216.htm. Acesso em: 22 out. 2016.

BRASIL. Ministério da Saúde. Gabinete do Ministro. Portaria $n^{\circ} 336$, de 19 de fevereiro de 2002. 2002. Disponível em: http://bvsms.saude.gov.br/bvs/saudelegis/gm/2002/ prt0336_19_02_2002.html. Acesso em: 10 out. 2016.

BRASIL. Presidência da República. Casa Civil. Subchefia para Assuntos Jurídicos. Decreto $n^{\circ}$ 6.949, de 25 de agosto de 2009. Promulga a Convenção Internacional sobre os Direitos das Pessoas com Deficiência e seu Protocolo Facultativo, assinados em Nova York, em 30 de março de 2007. 2009. Disponível em: http://www.planalto.gov.br/ccivil_03/_ato2007-2010/2009/ decreto/d6949.htm. Acesso em: 20 out. 2016.

BRASIL. Ministério da Saúde. Gabinete do Ministro. Portaria $n^{\circ} 4.279$, de 30 de dezembro de 2010. Estabelece diretrizes para a organização da Rede de Atenção à Saúde no âmbito do Sistema Único de Saúde (SUS). 2010. Disponível em: http://bvsms. saude.gov.br/bvs/saudelegis/gm/2010/prt4279_30_12_2010. html. Acesso em: 12 out. 2016.

BRASIL. Presidência da República. Casa Civil. Subchefia para Assuntos Jurídicos. Decreto $n^{\circ} 7.508$, de 28 de junho de 2011. Regulamenta a Lei $\mathrm{n}^{\circ} 8.080$, de 19 de setembro de 1990, para dispor sobre a organização do Sistema Único de Saúde - SUS, o planejamento da saúde, a assistência à saúde e a articulação interfederativa, e dá outras providências. 2011a. Disponível em: http://www.planalto.gov.br/ccivil_03/_ato2011-2014/2011/ decreto/d7508.htm. Acesso em: 16 out. 2016.

BRASIL. Ministério da Saúde. Gabinete do Ministro. Portaria $n^{\circ} 3.088$, de 23 de dezembro de 2011. Institui a Rede de Atenção Psicossocial para pessoas com sofrimento ou transtorno mental e com necessidades decorrentes do uso de crack, álcool e outras drogas, no âmbito do Sistema Único de Saúde (SUS). 2011b. Disponível em: http://bvsms.saude.gov.br/bvs/saudelegis/ gm/2011/prt3088_23 12 2011 rep.html. Acesso em: 20 out. 2016.

BRASIL. Presidência da República. Casa Civil. Subchefia para Assuntos Jurídicos. Lei $n^{\circ}$ 12.764, de 27 de dezembro de 2012. Institui a Política Nacional de Proteção dos Direitos da Pessoa com Transtorno do Espectro Autista; e altera o $\S 3^{\circ}$ do art. 98 da Lei $n^{\circ} 8.112$, de 11 de dezembro de 1990. 2012a. Disponível em: http://www.planalto.gov.br/ccivil_03/_ato2011-2014/2012/lei/ 112764.htm. Acesso em: 15 out. 2016 .

BRASIL. Ministério da Saúde. Gabinete do Ministro. Portaria $n^{\circ}$ 793, de 24 de abril de 2012. Institui a Rede de Cuidados à Pessoa com Deficiência no âmbito do Sistema Único de Saúde. 2012b. Disponível em: http://bvsms.saude.gov.br/bvs/ saudelegis/gm/2012/prt0793_24_04_2012.html. Acesso em: 17 out. 2016.
BRASIL. Ministério da Saúde. Secretaria de Atenção à Saúde. Portaria $n^{\circ} 854$, de 22 de agosto de 2012. 2012c. Disponível em: http://bvsms.saude.gov.br/bvs/saudelegis/sas/2012/ prt0854_22_08_2012.html. Acesso em: 18 out. 2016.

BRASIL. Ministério da Saúde. Secretaria de Atenção à Saúde. Departamento de Ações Programáticas Estratégicas. Linha de Cuidado para a atenção às pessoas com Transtornos do Espectro do Autismo e suas famílias na Rede de Atenção Psicossocial do SUS. Brasília: Ministério da Saúde, 2013.

BRASIL. Ministério da Saúde. Secretaria de Atenção à Saúde. Departamento de Ações Programáticas e Estratégicas. Área Técnica de Saúde da Pessoa com Deficiência. Diretrizes de atenção à reabilitação da pessoa com transtornos do espectro do Autismo (TEA). Brasília: Ministério da Saúde, 2014.

DINIZ, Débora. O que é deficiência. São Paulo: Brasiliense, 2007.

ELIA, Luciano. Psicanálise e neurociência face ao autismo: uma disjunção inclusiva. In: FURTADO, Luis Achilles Rodrigues; VIEIRA, Camilla Araújo Lopes (Org.). O autismo, o sujeito e a psicanálise: consonâncias. Curitiba: CRV, 2014. p. 19-38.

FREUD, Sigmund. Linhas de progresso na terapia psicanalítica (1919[1918]). In: SALOMÃO, Jayme (Org.). Obras Psicológicas Completas de Sigmund Freud. Rio de Janeiro: Imago, 2006. v. 17, p. 171-181. Edição Standard Brasileira.

FURTADO, Luis Achilles Rodrigues. Sua majestade o autista: fascínio, intolerância e exclusão no mundo contemporâneo. Curitiba: CRV, 2013.

GAZZINELLI, Maria Flávia et al. Educação em saúde: conhecimentos, representações sociais e experiências da doença. Cadernos de Saúde Pública, Rio de Janeiro, v. 21, n. 1, p. 200-206, jan./fev. 2005. http://dx.doi.org/10.1590/S0102$311 \mathrm{X} 2005000100022$

HORA, Dinair Leal da et al. Propostas inovadoras na formação do profissional para o Sistema Único de Saúde. Trabalho, Educação e Saúde, Rio de Janeiro, v. 11, n. 3, p. 471-486, set./dez. 2013. http://dx.doi.org/10.1590/S198177462013000300002

OLIVEIRA, Francisco Arsego. Antropologia nos serviços de saúde: integralidade, cultura e comunicação. Interface (Botucatu), Botucatu, v. 6, n. 10, p. 63-74, fev. 2002. http:// dx.doi.org/10.1590/S1414-32832002000100006

ORLANDI, Eni Puccinelli. Análise de Discurso: princípios \& procedimentos. 3. ed. Campinas: Pontes, 2001.

ORTEGA, Francisco. O sujeito cerebral e o movimento da neurodiversidade. Mana, Rio de Janeiro, v. 14, n. 2, p. 477-509, out. 2008. http://dx.doi.org/10.1590/S010493132008000200008

PACHECO, Ana Laura Prates. Autismo, Psicanálise e Saúde Pública. A peste: Revista de Psicanálise e Sociedade e Filosofia, São Paulo, v. 4, n. 2, p. 101-103, jul./dez. 2012. Disponível em: http://revistas.pucsp.br/apeste/article/view/22118. Acesso em: 26 abr. 2017.

PARDO, Hector Gonzalez; ALVAREZ, Marino Perez. La invención de transtornos mentales: escuchando al fármaco o al paciente? Madrid: Alianza, 2007 
RIBEIRO, Maria Anita Carneiro; MARTINHO, Maria Helena; MIRANDA, Elisabeth da Rocha. O sujeito autista e seus objetos. A peste: Revista de Psicanálise e Sociedade e Filosofia, São Paulo, v. 4, n. 2, p. 77-89, jul./dez, 2012. Disponível em: https://revistas.pucsp.br/apeste/article/view/22116/0. Acesso em: 14 maio 2016.

ROSSONI, Eloá; LAMPERT, Jadete. Formação de Profissionais para o Sistema Único de Saúde e as Diretrizes Curriculares. Boletim da Saúde, Porto Alegre, v. 18, n. 1, p. 87-98, jan./ jun. 2004. Disponível em: http://bvsms.saude.gov.br/bvs/ periodicos/boletim saude v18n1.pdf\#page $=86$. Acesso em: 15 ago. 2017.

ROUDINESCO, Elisabeth; PLON, Michel. Dicionário de Psicanálise. Tradução de Vera Ribeiro e Lucy Magalhães; supervisão da edição brasileira Marco Antonio Coutinho Jorge. Rio de Janeiro: J. Zahar, 1998. 